J. Amer. Soc. Hort. Sci. 116(4):693-696. 1991.

\title{
Enhanced Vegetative Growth and Development of Processing Tomato by DCPTA Treatment of Seed
}

\author{
J.H. Keithly, H. Kobayashi ${ }^{1}$, and H. Yokoyama \\ U.S. Department of Agriculture, Agricultural Research Service, Fruit and Vegetable Chemistry \\ Laboratory, 263 S. Chester Avenue, Pasadena, CA 91106
}

\author{
H.W. Gausman \\ Cropping Systems Research Laboratory, Route 3, Box 215, Lubbock TX 79401 \\ Additional index words. Lycopersicon esculentum, bioregulator, fruit quality
}

Abstract. Application of DCPTA as a pregermination seed treatment (DCPTA plants) increased the seedling vigor, relative growth rate, harvestable yield, and yield quality of processing tomato (Lycopersicon esculentum Mill. CVs. UC82, VF6203, H100). When compared with controls, the growth rates of roots and shoots of $30 \mu \mathrm{M}$ DCPTA plants were increased significantly $(P=0.05)$ during seed germination and midexponential growth. At fruit harvest, greenhouse-grown $30 \mu \mathrm{M}$ DCPTA plants showed a 2- to 3-fold increase in leaf, stem, and root dry weight compared with that of controls. Improvements in the uniformity of fruit maturation significantly increased the harvestable fruit yields of greenhouse-grown DCPTA plants compared with that of controls. The total soluble solids ( ${ }^{\circ}$ Brix), glucose, fructose, and carotenoid contents of red-ripe fruits harvested from greenhouse- and field-grown DCPTA plants were significantly increased compared with controls. Chemical name used: 2-(3,4-dichlorophenoxy)triethylamine (DCPTA).

The productivity of processing tomato is determined by the harvestable fruit yield (kilograms per plant per unit production area) and by the total soluble solids (SSC) and carotenoid contents of the ripe fruits (Stevens, 1986). However, negative relationships between fruit yield and quality are generally observed (Stevens, 1986). In addition, photosynthate partitioning to lateseason vegetative growth often competes unfavorably against fruit development that may reduce both the harvestable yield and the SSC of ripe fruits (Frost and Kretchman, 1987a, 1987b; Ho, 1984). In a previous study, the tertiary amine bioregulator DCPTA significantly improved the vegetative growth and harvestable yield of the fresh-market tomato cultivar Pixie (Keithly et al., 1990b). Improvements in the fruit yield of plants derived from seeds that had been treated with $30 \mu \mathrm{M}$ DCPTA (DCPTA plants) were related to a significantly accelerated secondary branch development during exponential plant growth. Within the treated group, no negative relationships between vegetative plant growth and fruit maturation were observed. In this study, we examine the effects of DCPTA on the harvestable yield and yield quality of processing tomato cultivars UC82, H100, and VF6203. The carotenoid and SSC of ripe fruits harvested from greenhouseand field-grown DCPTA plants are examined.

\section{Materials and Methods}

Chemicals. DCPTA was synthesized and purified by the methods of Poling et al. (1977) and Echols et al. (1981). All other chemicals were obtained from commercial supply houses.

Seed germination and greenhouse studies. All bioregulator solutions were prepared using distilled water. Solutions of 3 , 30, or $300 \mu \mathrm{M}$ DCPTA ( $\mathrm{pH} 4.3$ ) contained $0.1 \%$ Tween $80(\mathrm{v} / \mathrm{v})$ as a surfactant. Tomato seeds (CVs. UC82, VF6203, and H100; Beatrice/Hunt-Wesson, Inc., Fullerton, Calif.) were soaked in

Received for publication 18 May 1990. Reference to company name or product name does not imply approval or recommendation of the product by the U.S. Dept. of Agriculture to the exclusion of others that may be suitable. The cost of publishing this paper was defrayed in part by the payment of page charges. Under postal regulations, this paper therefore must be hereby marked advertisement solely to indicate this fact.

${ }^{1}$ Present address: Nittoh Bion Co., Ltd., Bioscience Research Center, 436-7 Kitagami, Kitami, Hokkaido 099-15, Japan.
DCPTA solutions for $6 \mathrm{~h}$ at 24C. Control seed lots were soaked for $6 \mathrm{~h}$ at $24 \mathrm{C}$ in $0.1 \%$ Tween $80(\mathrm{v} / \mathrm{v}, \mathrm{pH} 4.3)$. For seed germination studies, DCPTA-treated seeds were germinated in the dark at $28 \mathrm{C}$ using a ragdoll seed germination method (Gausman et al., 1988). After $96 \mathrm{~h}$ of incubation, primary root and hypocotyl lengths of the germinated seeds were determined. For plant growth studies, DCPTA-treated seeds were planted in 11.5liter plastic pots filled with 2 fir bark: 2 redwood bark: 1 sphagnum peat : 1 sand (by volume). Seedling plants were thinned to one plant per pot and were fertilized weekly with $3 \mathrm{~g} 20 \mathrm{~N}-$ $7 \mathrm{P}-17 \mathrm{~K} /$ liter that contained chelated iron and micronutrients. The greenhouse where the plants were grown was maintained at a $28 \pm 4 \mathrm{C} / 20 \pm 2 \mathrm{C}$ day/night cycle. Plants received a photosynthetic photon flux (PPF) of 1200 to $1400 \mu \mathrm{mol} \cdot \mathrm{s}^{-1} \cdot \mathrm{m}^{-2}$ photosynthetically active radiation (PAR) and the photoperiod was extended to $14 \mathrm{~h}$ using metal halide lamps (PPF at plant height, $\left.450 \mu \mathrm{mol} \cdot \mathrm{s}^{-1} \cdot \mathrm{m}^{-2} \mathrm{PAR}\right)$. Each plant was an experimental unit and each DCPTA treatment group contained 40 replicates. All plants were arranged as a completely randomized-block experimental design. For plant growth determinations, six plants were harvested from each DCPTA treatment group.

Plant growth and fruit yield determinations. Plants were harvested 111 days after seed planting and were separated into leaf, stem, root, and fruit samples. Dry weights of leaf, stem, and root samples were obtained after drying to constant weight at 75C. Leaf areas were determined using a Delta $\mathrm{T}$ video leaf area meter (Decagon Devices, Pullman, Wash.). Fruits <35 $\mathrm{mm}$ in diameter were discarded before harvestable yield determinations. Total fruit yields, fruit number per plant, and percentage of red-ripe, U.S. Dept. of Agriculture color code 6 fruits (U.S. Dept. Agr., 1976) were determined. Analysis of variance (ANOVA) was performed for all growth and yield data. Percentile data were transformed to arcsin values before ANOVA (Zar, 1974). Linear and quadratic regression analyses were performed for all data (Zar, 1974).

Fruit constituents analyses. Carbohydrate and carotenoid analyses were determined using red-ripe fruits harvested 42 days after anthesis. Samples obtained from four fruits (100 g total fresh weight) were combined and were homogenized in acetone $(100 \%)$ using a polytron. Total fruit carotenoids were extracted 
into acetone and the extracts were saponified (Benedict et al., 1985). Lycopene and beta-carotene were spectrophotometrically quantified (Davies, 1965) after separation using MgO : Hyflo Supercel $(1: 1, \mathrm{w} / \mathrm{w})$ column chromatographic methods (Hsu et al., 1989). The SSC ( ${ }^{\circ}$ Brix) of mature fruits was determined by analytical refractometry (Horwitz, 1980). Total soluble solids extracts were separated into neutral, acidic, and basic fractions by ion-exchange chromatography (Atkins and Canvin, 1971). Fructose and glucose were determined by high performance liquid chromatography using a Whatman Partisil 10 analytical carbohydrate column and a refractive index detector. The mobile phase was acetonitrile : water : $1 \% \mathrm{NH}_{4} \mathrm{OH}(80: 20: 1, \mathrm{v} / \mathrm{v})$ eluted at a $2.0 \mathrm{ml} \cdot \mathrm{min}^{-1}$ flow rate.

Field studies. Seeds of 'VF6203' and 'H100' tomatoes were soaked in solutions of DCPTA as described for greenhouse studies. Then, seeds were air-dried at $24 \mathrm{C}$ for $48 \mathrm{~h}$. Plants were grown in 1987 near Bakersfield, Calif., on a Wasco sandy loam (mixed-loamy, mesic, orthothillic, toriothents). Tomato seeds were mechanically planted and seedlings were hand-thinned to 45 seedlings/m at the four true-leaf stage of plant growth. Experimental rows were $30 \mathrm{~m}$ long, spaced $2 \mathrm{~m}$ apart, and were replicated three times each in two field locations. Plants were grown using conventional furrow irrigation and $\mathrm{N}-\mathrm{P}-\mathrm{K}$ application methods for commercial tomato production. Ripe fruits ( $5 \mathrm{~kg}$ per DCPTA-treatment group) were harvested by random selection 186 days after seed planting. At fruit harvest, red-ripe fruits represented $85 \%$ to $90 \%$ of the total fruit yield per plant in control and all DCPTA-treatment groups. Carbohydrate and carotenoid analyses of field-grown fruits were determined as described for greenhouse-grown fruits.

\section{Results}

Application of $30 \mu \mathrm{M}$ DCPTA as a pregermination seed treatment significantly increased the seedling vigor of all three cultivars as determined by primary root and hypocotyl elongation (Table 1). When compared with the growth of controls, the 300$\mu \mathrm{M}$ DCPTA treatment significantly reduced tomato seedling development. When compared with that of controls, the accelerated root and shoot development of plants derived from seeds

Table 1. Root and hypocotyl length of tomato seedlings in response to DCPTA treatment.

\begin{tabular}{lccc}
\hline \hline \multicolumn{1}{c}{ Cultivar } & $\begin{array}{c}\text { DCPTA } \\
(\mu \mathrm{M})\end{array}$ & $\begin{array}{c}\text { Root length } \\
(\mathrm{mm})\end{array}$ & $\begin{array}{c}\text { Hypocotyl length } \\
(\mathrm{mm})\end{array}$ \\
\hline H100 & 0 & $43^{\mathrm{z}}$ & 19 \\
& 3 & 48 & 21 \\
& 30 & 63 & 30 \\
Significance & 300 & 44 & 15 \\
VF6203 & & $\mathrm{L}^{\mathrm{Ns}} \mathrm{Q}^{*}$ & $\mathrm{~L}^{\mathrm{Ns}} \mathrm{Q}^{*}$ \\
& 0 & 34 & 17 \\
& 3 & 46 & 22 \\
Significance & 30 & 57 & 29 \\
UC82 & 300 & 42 & 18 \\
& & $\mathrm{~L}^{\mathrm{NS}} \mathrm{Q}^{*}$ & $\mathrm{~L}^{\mathrm{NS}} \mathrm{Q}^{*}$ \\
& 3 & 31 & 16 \\
Significance & 30 & 39 & 21 \\
\hline
\end{tabular}

${ }^{2}$ Data represent mean values from four independent experiments. $\mathrm{n}=$ 50.

NS. *Nonsignificant or significant at $P=0.05$, respectively. $\mathrm{L}=$ linear; $\mathrm{Q}=$ quadratic. treated with DCPTA at $30 \mu \mathrm{M}$ (30 DCPTA plants) was maintained throughout exponential growth and is typified by the vegetative growth of 'VF6203' plants (Fig. 1). During the midexponential growth (40 to 50 days after seed planting) of such plants, the mean relative growth rates (Evans, 1972) of leaves, stems, and roots were increased, 38\%, 43\%, and 58\%, respectively, compared with controls. The leaf area development of control and 30 DCPTA plants paralleled the observed increases in leaf dry weight (linear correlation coefficient, $r=0.87$ ). At fruit harvest (111 days after seed planting), the dry weights of these plants showed a 2 - to 3 -fold increase over the vegetative growth of controls. Similarly, 30 DCPTA plants of 'H100' and 'UC82' showed significant improvements in relative growth rate and biomass accumulation compared with the growth of controls (data not presented).

When compared with that of controls, seed-treatment application of DCPTA significantly increased the total fruit set of 'H100', 'VF6203', and 'UC82' plants (Table 2). The individual fruit size of red-ripe fruits harvested from 'H100' and 'VF6203' plants was significantly increased by the application of DCPTA to ungerminated seeds (Table 2). However, compared with controls, 30- $\mu$ M DCPTA application to 'UC82' seeds resulted in nonsignificant improvements in fruit size (Table 2). In the three tomato cultivars that were tested, 30- $\mu \mathrm{M}$ DCPTA application significantly increased the percentage of red-ripe fruits and fruit yield of mature plants 111 days after seed planting (Table 2). Significant quadratic responses indicated that 300- $\mu$ M DCPTA seed treatments inhibited the fruit set and harvestable fruit yield of processing tomato (Table 2). The lycopene and beta-carotene contents of mature fruits harvested from 30 DCPTA plants were doubled compared with the carotenoid development of ripe control fruits (Table 3). In 30 DCPTA plants of 'H100', 'VF6203', and 'UC82', the SSC of ripe fruits was increased $20 \%, 27 \%$, and $8.8 \%$, respectively, compared with controls. About equal amounts of glucose and fructose and trace amounts of sucrose were present in all fruits that were analyzed. The glucose and

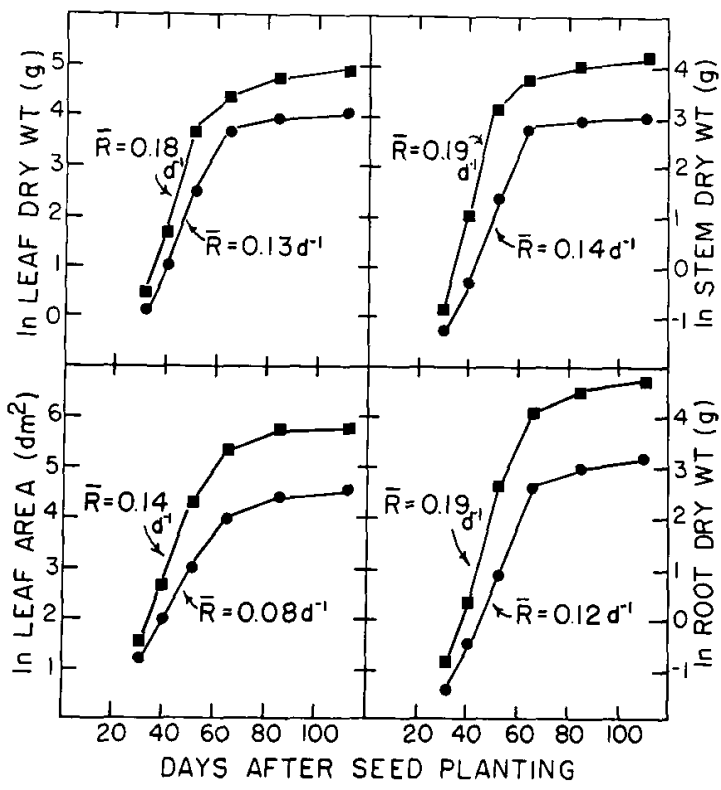

Fig. 1. Effect of DCPTA seed treatment on the vegetative growth of greenhouse-grown processing tomato. Data represent the mean of six replicates. Mean relative growth rates $\left(\mathrm{R}\right.$, unit: day ${ }^{-1}$, were determined between 40 and 50 days after seed planting. Control, $\mathbf{0}$; $30 \mu \mathrm{M}$ DCPTA, 
Table 2. Effect of DCPTA on the yield of greenhouse-grown processing tomato (fruits were harvested 111 days after seed planting).

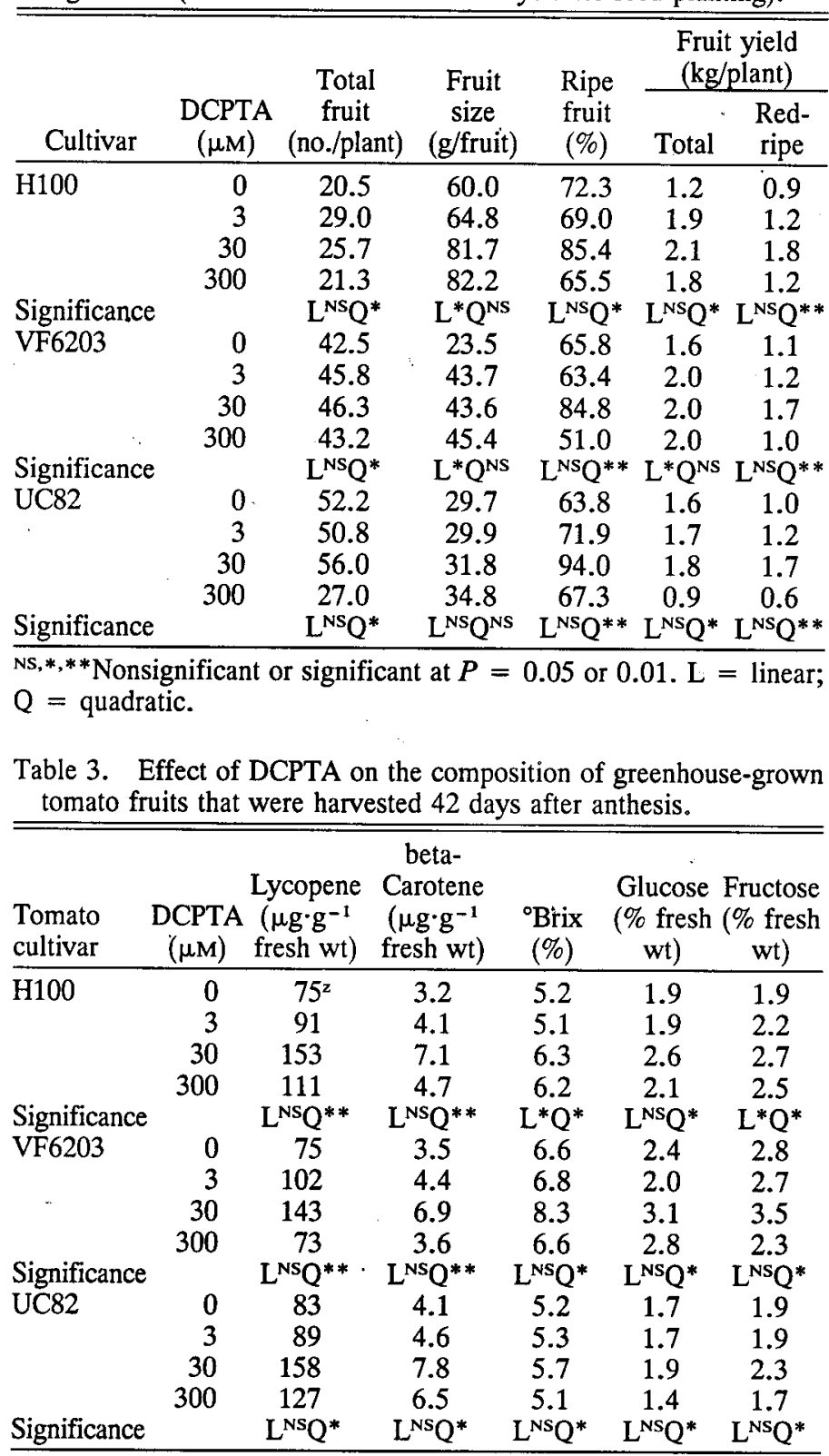

${ }^{2}$ Data represent mean values from six independent fruit samples. NS.*,**Nonsignificant or significant at $P=0.05$ or 0.01 , respectively, $\mathrm{L}=$ linear; $\mathrm{Q}=$ quadratic.

plants were increased significantly $(P=0.05)$ compared with the sugar content of ripe control fruits.

Application of DCPTA as a pregermination seed treatment significantly improved the fruit quality of field-grown 'VF6203' and 'H100' plants (Table 4). The carotenoid and sugar contents of ripe fruits harvested from 30 DCPTA plants increased significantly ( $P=0.05$ ) compared with that of controls. The fruit yield per hectare of field-grown plants was not determined. However, compared with controls, $30 \mu \mathrm{M}$ DCPTA visually neither reduced fruit yield per plant nor reduced the percentage of ripe fruits per plant at fruit harvest.

\section{Discussion}

This study documents the effective use of DCPTA as a seed treatment to enhance the vegetative growth and yield productiv-
Table 4. Effect of DCPTA on fruit quality of field-grown processing tomato.

\begin{tabular}{|c|c|c|c|c|c|c|}
\hline Cultivar & $\begin{array}{c}\text { DCPTA } \\
(\mu \mathrm{M})\end{array}$ & $\begin{array}{l}{ }^{\circ} \mathrm{Brix} \\
(\%)\end{array}$ & $\begin{array}{c}\text { Glucose } \\
\text { (\% fresh } \\
\text { wt) }\end{array}$ & $\begin{array}{c}\text { Fructose } \\
\text { (\% fresh } \\
\text { wt) }\end{array}$ & $\begin{array}{l}\text { Lycopene } \\
\left(\mu g \cdot g^{-1}\right. \\
\text { fresh wt) }\end{array}$ & $\begin{array}{c}\text { beta- } \\
\text { Carotene } \\
\left(\mu g \cdot g^{-1}\right. \\
\text { fresh } w t)\end{array}$ \\
\hline \multirow[t]{4}{*}{$\overline{\mathrm{H} 100}$} & 0 & $5.5^{z}$ & 1.8 & 2.1 & 79 & 4.3 \\
\hline & 3 & 5.3 & 2.0 & 2.0 & 84 & 4.3 \\
\hline & 30 & 6.3 & 2.1 & 3.2 & 134 & 5.8 \\
\hline & 300 & 6.2 & 2.1 & 3.2 & 166 & 6.0 \\
\hline Significance & & $\mathrm{L}^{*} \mathrm{Q}^{\mathrm{NS}}$ & $\mathrm{L}^{*} \mathrm{Q}^{\mathrm{NS}}$ & $\mathrm{L}^{*} \mathrm{Q}^{\mathrm{NS}}$ & $\mathrm{L}^{* *} \mathrm{Q}^{\mathrm{NS}}$ & $\mathrm{L}^{*} \mathrm{Q}^{\mathrm{NS}}$ \\
\hline \multirow[t]{4}{*}{ VF6203 } & 0 & 5.1 & 2.0 & 2.3 & 82 & 4.2 \\
\hline & 3 & 5.5 & 2.3 & 2.6 & 87 & 4.3 \\
\hline & 30 & 6.3 & 2.2 & 2.9 & 169 & 5.7 \\
\hline & 300 & 6.1 & 2.0 & 3.8 & 128 & 5.0 \\
\hline Significance & & $\mathrm{L}^{*} \mathrm{Q}^{\mathrm{NS}}$ & $\mathrm{L}^{*} \mathrm{Q}^{*}$ & $\mathrm{~L}^{*} \mathrm{Q}^{\mathrm{NS}}$ & $\mathrm{L}^{*} \mathrm{Q}^{*}$ & $\mathrm{~L}^{\mathrm{NS}} \mathrm{Q}^{*}$ \\
\hline
\end{tabular}

${ }^{2}$ Data represent mean values from six independent fruit samples. NS, $* * *$ Nonsignificant or significant at $P=0.05$ or 0.01 , respectively. $\mathrm{L}=$ linear; $\mathrm{Q}=$ quadratic.

ities of processing tomato. During the early stages of fruit development, tomato fruits represent relatively weak photoassimilate sinks against late-season vegetative growth (Ho, 1984; Stevens, 1986). Excessive vegetative growth can often reduce fruit set and the percentage of red-ripe fruits at plant harvest (Frost and Kretchman, 1987a, 1987b; Stevens, 1986). In DCPTA plants of 'H100', 'VF6203', and 'UC82', significant biomass gains were manifested in all plant parts (Fig. 1). In 30 DCPTA plants, seedling vigor (Table 1) and the mid-exponential growth rate of shoot and roots (Fig. 1) were significantly enhanced. However, all plants showed similar reductions in growth rate at 65 days after seed planting (Fig. 1). These results demonstrate that the enhanced vegetative biomass of 30 DCPTA plants is not due to a DCPTA-mediated extension of exponential growth. In addition, the harvestable yield (Table 2) and yield quality (Table 3) of greenhouse-grown 30 DCPTA plants were significantly increased relative to controls. These results further indicate that, in DCPTA plants, competitive sink use of photosynthate was adequately balanced between vegetative and reproductive sinks.

The SSC of red-ripe tomato fruit is regulated by the rate of starch deposition in newly set fruit (Dinar and Stevens, 1981; Ho, 1984). Tomato genotypes high in SSC are characterized as having high rates of starch deposition and a high photoassimilate sink strength (Hewitt et al., 1982). Tomato cultivars H100 and VF6203 are characterized as genotypes high in SSC relative to 'UC82' fruits (Hunt/Wesson Foods, personal communication). In greenhouse studies, the SSC and glucose and fructose contents of 'H100' and 'VF6203' fruits harvested from 30 DCPTA plants showed significantly larger increases over controls relative to the SSC and sugar contents of 'UC82' fruits harvested from 30 DCPTA plants (Table 3). These results indicate that, in processing tomato, the improvement of crop performance by DCPTA is highly dependent on the variable strength of newly set fruits to import photosynthate. In DCPTA plants, the enhanced biomass gains of all plant parts would possibly require a significantly increased net-carbon fixation per unit leaf area in mature leaves to support competitive vegetative and reproductive sinks. In 30 DCPTA plants of spinach (Keithly and Yokoyama, 1988) and sugarbeet (Keithly et al., 1990a), enhanced vegetative growth rates were related to improvements in the chloroplast compartment size, in vitro ribulose-1,5-bisphosphate carboxylase/oxygenase activity, and in net-carbon fixation per unit leaf area of mature leaves. 
The commercial production of canned tomato products is an energy-intensive process (Singh, 1980). Cost per ton of the finished tomato product (catsup, tomato sauce, tomato paste) is highly correlated to the original SSC of the fresh tomato fruit (Singh, 1980). Tomato product quality further depends on the carotenoid content of the finished product. This study has shown the lycopene and beta-carotene contents of ripe tomato fruits harvested from greenhouse- and field-grown 30 DCPTA plants to be significantly greater than the carotenoid accumulation of controls (Tables 3 and 4). These results demonstrate the multifunctional use of DCPTA to enhance photosynthate supply and use, and specifically to regulate carotenoid biosynthesis (Yokoyama et al., 1982) in carotertogenic fruits.

\section{Literature Cited}

Atkins, C.A. and D.T. Canvin. 1971. Photosynthesis and $\mathrm{CO}_{2}$ evolution by leaf discs: gas exchange, extraction, and ion-exchange fractionation of ${ }^{14} \mathrm{C}$-labeled photosynthetic products. Can. J. Bot. 49:1225-1234.

Benedict, C.R., C.L. Rosenfield, J.R. Mahan, S. Madhavan, and H. Yokoyama. 1985. The chemical regulation of carotenoid biosynthesis in Citrus. Plant Sci. 41:168-173.

Davies, B.H. 1965. Analysis of carotenoid pigments, p. 489-532. In: T.W. Goodwin (ed.). Chemistry and biochemistry of plant pigments Academic, New York.

Dinar, M. and M.A. Stevens. 1981. The relationship between starch accumulation and soluble solids content of tomato fruits. J. Amer. Soc. Hort. Sci. 106:415-418.

Echols, L.C., V.P. Maier, S.M. Poling, and P.R. Sterling. 1981. New bioregulators of gibberellin biosynthesis in Gibberella fujikuroi. Photochemistry 20:433-437.

Evans, G.C. 1972. The quantitative analysis of plant growth, p. 198200. Univ. of Calif. Press, Berkeley.

Frost, D.R. and D.W. Kretchman. 1987a. Influence of dikegulac on the growth of processing tomatoes. HortScience 22:232-234.

Frost, D.R. and D.W. Kretchman. 1987b. Use of growth retardants to improve ripening uniformity and yield of processing tomatoes. HortScience 22:422-423.

Gausman, H.W., H. Yokoyama, J.E. Quisenberry, J.H. Keithly, and
J.D. Burd. 1988. Effects of diethylaminoethyl-3,4-dichlorophenylether (DCPTA) on cotton (Gossypium hirsutum L.) root/shoot ratio. Bul. Plant Growth Reg. Soc. Amer. 16:6-7.

Hewitt, J. D., M. Dinar, and M.A. Stevens. 1982. Sink strength of fruits of two tomato genotypes differing in total solids content. J. Amer. Soc. Hort. Sci. 107:896-900.

Ho, L.C. 1984. Partitioning of assimilates in fruiting tomato plants. Plant Growth Regulat. 2:277-285.

Horwitz, W. 1980. Official methods of analysis of the association of official analytical chemists, 13th ed. Assn. Offic. Anal. Chem. Washington D.C. p. 363.

Hsu, W.J., C. DeBenedict, S.D. Lee, S.M. Poling, and H. Yokoyama. 1989. Preharvest prevention of regreening in Valencia oranges (Citrus sinensis (L.) Osbeck). J. Agr. Food Chem. 37:12-14.

Keithly, J.H. and H. Yokoyama. 1988. Chemical regulation of growth and photosynthesis of spinach by 2-(3,4-dichlorphenoxy)triethylamine [DCPTA]. Amer. Chem. Soc., Los Angeles, Calif. AGFD:20. (Abstr.)

Keithly, J.H., H. Yokoyama, and H.W. Gausman. 1990a. Effect of 2-(3,4-dichlorphenoxy) triethylamine [DCPTA] upon the growth and development of sugar beet. Plant Sci. 68:57-64.

Keithly, J.H., H. Yokoyama, and H.W. Gausman. 1990b. Enhanced yield of tomato in response to 2-(3,4-dichlorophenoxy) triethylamine (DCPTA). Plant Growth Regulat. 9:127-136.

Poling, S.M., W.J. Hsu, and H. Yokoyama. 1977. Structure activity relationships of chemical inducers of carotenoid biosynthesis. Phytochemistry 14:1933-1938.

Singh, R.P., A. Carroad, M.S. Chhinnah, W.W. Rose, and N.L. Jacob. 1980. Energy accounting in canning tomato products. J. Food Sci. 45:735-739.

Stevens, M.A. 1986. Inheritance of tomato fruit quality components. Plant Breeding Rev. 4:273-311.

U.S. Department of Agriculture. 1976. United States standards for grades of fresh tomatoes. U.S. Dept. Agr., Agr. Mktg. Serv., Washington, D.C.

Yokoyama, H., W,J. Hsu, S.M. Poling, and E.P. Hayman. 1982. Chemical regulation of carotenoid biosynthesis, p. 371-385. In: G. Britton and T.W. Goodwin (eds.). Carotenoid chemistry and biochemistry. Pergamon, Oxford.

Zar, J.H. 1974. Biostatistical analysis. Prentice-Hall, Englewood Cliffs, N.J. 